\title{
Miconazole induces autophagic death in glioblastoma cells via reactive oxygen species-mediated endoplasmic reticulum stress
}

\author{
HUI-JUNG JUNG ${ }^{1}$, INCHEOL SEO ${ }^{2}$, BIJAY KUMAR JHA ${ }^{3}$, SEONG-IL SUH ${ }^{1}$ and WON-KI BAEK ${ }^{1,4}$ \\ ${ }^{1}$ Department of Microbiology, School of Medicine, Keimyung University, Dalseogu, Daegu 42601; \\ ${ }^{2}$ Department of Microbiology, Dongguk University College of Medicine, Gyeongju 38066, Republic of Korea; \\ ${ }^{3}$ Division of Infectious Diseases, Department of Internal Medicine, Ohio State University Wexner Medical Center, \\ Columbus, OH 43210, USA; ${ }^{4}$ Institute for Cancer Research, Keimyung University \\ Dongsan Medical Center, Dalseogu, Daegu 42601, Republic of Korea
}

Received April 8, 2020; Accepted January 28, 2021

DOI: $10.3892 / \mathrm{ol} .2021 .12596$

\begin{abstract}
Miconazole is an antifungal agent that is used for the treatment of superficial mycosis. However, recent studies have indicated that miconazole also exhibits potent anticancer effects in various types of cancer via the activation of apoptosis. The main aim of the present study was to observe the effect of miconazole on autophagic cell death of cancer cells. Cytotoxicity was measured by viable cell counting after miconazole treatment in glioblastoma cell lines (U343MG, U87MG and U251MG). Induction of autophagy was analyzed by examining microtubule-associated protein light chain 3 (LC3)-II expression levels using western blotting and by detecting GFP-LC3 translocation using a fluorescence microscope. Intracellular ROS production was measured using a fluorescent probe, 2',7'-dichlorodihydrofluorescein diacetate. It was found that miconazole induced autophagic cell death in the U251MG glioblastoma cell line via the generation of reactive oxygen species (ROS) and endoplasmic reticulum (ER) stress response. An association between miconazole-induced ROS production and autophagy was also identified; in particular, pretreatment of the cells with a ROS scavenger resulted
\end{abstract}

Correspondence to: Professor Won-Ki Baek, Department of Microbiology, School of Medicine, Keimyung University, 1095 Dalgubeoldaero, Dalseogu, Daegu 42601, Republic of Korea E-mail: wonki@dsmc.or.kr

Abbreviations: 3-MA, 3-methyladenine; 4-PBA, 4-phenylbutyric acid; ATG5, autophagy protein 5; Baf A1, bafilomycin A1; BiP, binding immunoglobulin protein; CQ, chloroquine; DMEM, Dulbecco's Modified Eagle's medium; EDTA, ethylenediaminetetraacetic acid; eIF2 $\alpha$, eukaryotic translation initiation factor $2 \alpha$; ER, endoplasmic reticulum; $\mathrm{H}_{2}$ DCFDA, 2',7'-dichlorodihydrofluorescein diacetate; IRE1 $\alpha$, inositol-requiring enzyme $1 \alpha$; LC3, microtubule-associated protein light chain 3; NAC, N-acetylcysteine; p-, phospho-; PBS, phosphate-buffered saline; ROS, reactive oxygen species; siRNA, small interfering RNA

Key words: miconazole, autophagy, cell death, reactive oxygen species, endoplasmic reticulum stress in a reduction in the levels of LC3-II. Miconazole-induced ER stress was associated with increases in binding immunoglobulin protein $(\mathrm{BiP})$, inositol-requiring enzyme $1 \alpha(\mathrm{IRE} 1 \alpha)$ and CHOP expression, and phospho-eIF $2 \alpha$ levels. The inhibition of ER stress via treatment with 4-phenylbutyric acid or BiP knockdown reduced miconazole-induced autophagy and cell death. These findings suggest that miconazole induces autophagic cell death by inducing an ROS-dependent ER stress response in U251MG glioma cancer cells and provide new insights into the potential antiproliferative effects of miconazole.

\section{Introduction}

Macroautophagy, hereafter referred to as autophagy, is a cellular process of self-digestion, by which cellular proteins and organelles are removed and recycled. This process is important in cell growth and development and for the maintenance of cellular homeostasis $(1,2)$. Autophagy begins with the formation of double-membrane vesicles, known as autophagosomes, which fuse with lysosomes to form autophagolysosomes; the lysosomal hydrolases then degrade the vesicle contents for reuse (3). Autophagy is induced by intracellular and extracellular stresses, including hypoxia, starvation, oxidative stress, ischemia and chemotherapy (4-6). Autophagy promotes cell survival and cell death in cancer, according to the tumor microenvironment, stage, type and other factors $(7,8)$.

Numerous antifungal agents have shown cytotoxic effects against human cancer cells $(9,10)$, although the associated mechanisms are not clearly understood. Azoles are a main class of antifungal agents and are classified into two groups, namely triazoles and imidazoles. Miconazole is an imidazole derivative that is used as an antifungal agent to treat superficial fungal infections, including athlete's foot, ringworm and candidiasis. In addition, miconazole has been shown to inhibit the growth of various solid tumors, including glioma, breast cancer and osteosarcoma in humans (11-13). The in vivo therapeutic efficacy of miconazole has also been reported in human colon carcinoma xenografts in nude mice (14). Most previous studies have shown that the antiproliferative effects of miconazole are mediated by the induction of apoptosis $(15,16)$. In 
addition, miconazole has been reported to increase the production of reactive oxygen species (ROS) and raise intracellular $\mathrm{Ca}^{2+}$ levels, thereby killing rat embryonic cardiomyoblasts and human osteosarcoma cells via oxidative stress $(17,18)$. Moreover, miconazole has been shown to inhibit the growth of many types of cancer cells. For example, previous studies demonstrated that a combination of miconazole and artemisinin effectively inhibited the growth of bladder and breast cancer cell lines (11), and miconazole alone inhibited the proliferation of bladder cancer cells via the induction of $\mathrm{G}_{0} / \mathrm{G}_{1}$ cell cycle arrest and apoptosis (15). Another study showed that miconazole was non-cytotoxic to astrocytes and microglial BV2 cells, but ameliorated the neuroinflammation-mediated progression of Alzheimer's disease by blocking the expression of inducible nitric oxide synthase (19) which is also known to be related in cancer growth $(20,21)$. However, the precise mechanism of the anticancer effects of miconazole remain to be elucidated. Notably, another antifungal agent, itraconazole, has been shown to inhibit the proliferation of cancer cells by inducing autophagy (22).

Considering the abilities of miconazole and itraconazole to induce ROS production and autophagy, the aim of the present study was to examine whether miconazole induces autophagic death in cancer cells. The findings of this study may lead to the identification of a novel mechanism for the anticancer activity of miconazole.

\section{Materials and methods}

Cell lines and reagents. Human glioblastoma U343MG, U87MG (ATCC ${ }^{\circledR}$ HTB-14 ${ }^{\mathrm{TM}}$; glioblastoma of unknown origin) and U251MG cells and human breast cancer MDA-MB-231 cells (cat. no. HTB-26 ${ }^{\mathrm{TM}}$; ATCC) and human lung cancer A549 cells (cat. no. CCL-185 ${ }^{\mathrm{TM}}$; ATCC) were obtained from the American Type Culture Collection. All the cells were cultured in Dulbecco's Modified Eagle's Medium (DMEM), supplemented with $10 \%$ fetal bovine serum (HyClone; Cytiva) and $1 \%$ penicillin/streptomycin at $37^{\circ} \mathrm{C}$ in a humidified atmosphere of $5 \% \mathrm{CO}_{2}$. Miconazole, 3-methyladenine (3-MA), chloroquine (CQ), 4-phenylbutyric acid (4-PBA) and $\mathrm{N}$-acetylcysteine (NAC) were purchased from Sigma-Aldrich (Merck KGaA). Bafilomycin A1 (Baf A1) was purchased from LC Laboratories. The pan-caspase inhibitor z-VAD-fmk and human recombinant tumor necrosis factor-related apoptosis-inducing ligand (TRAIL) were purchased from R\&D Systems, Inc.

Cell treatments. To examine the effect of z-VAD-fmk, a pan-caspase inhibitor, on the cytotoxicity of miconazole, U251MG cells were pre-treated with z-VAD-fmk for $30 \mathrm{~min}$ at $37^{\circ} \mathrm{C}$, followed by miconazole treatment for $24 \mathrm{~h}$ at $37^{\circ} \mathrm{C}$. Autophagy inhibitors [3-MA (1 mM), Baf A1 $(20 \mathrm{nM})$ and CQ $(50 \mu \mathrm{M})]$ were treated simultaneously with miconazole for $24 \mathrm{~h}$ at $37^{\circ} \mathrm{C}$ in U251MG cells. In U251MG cells an endoplasmic reticulum (ER) stress inhibitor 4-PBA was pretreated for $30 \mathrm{~min}$ at $37^{\circ} \mathrm{C}$ followed by treatment with $20 \mu \mathrm{M}$ miconazole for $24 \mathrm{~h}$ at $37^{\circ} \mathrm{C}$. U251MG cells were pretreated with a ROS scavenger NAC $(5 \mathrm{mM})$ for $2 \mathrm{~h}$ at $37^{\circ} \mathrm{C}$ and then treated with miconazole 10 and $20 \mu \mathrm{M}$ for $24 \mathrm{~h}$ at $37^{\circ} \mathrm{C}$. U251 MG cells were treated with TRAIL $(50 \mathrm{ng} / \mathrm{ml})$ for $24 \mathrm{~h}$ at $37^{\circ} \mathrm{C}$.
Western blotting. Anti-78-kDa glucose-regulated protein [also known as binding immunoglobulin protein (BiP); sc-13968), anti-eukaryotic translation initiation factor $2 \alpha$ (eIF2 $\alpha$; sc-133132), anti-CHOP antibodies (sc-7351) and anti-pro caspase-3 (sc-7148) were purchased from Santa Cruz Biotechnology, Inc. Anti-inositol-requiring enzyme $1 \alpha$ (IRE1 $\alpha$; cat. no. 3294), anti-phospho-eIF $2 \alpha$ (p-eIF2 $\alpha$; cat. no. 9721), anti-cleaved caspase-3 (cat. no. 9661) and anti-autophagy protein 5 (ATG5; cat. no. 2630) antibodies were purchased from Cell Signaling Technology, Inc. An anti-microtubule-associated protein light chain 3 (LC3) antibody (PD014) was purchased from Medical and Biological Laboratories Co., Ltd. These antibodies were used at a dilution of 1:1,000. Anti- $\beta$-actin antibody (A5441) was acquired from Sigma-Aldrich (Merck KGaA) and used at a dilution of 1:5,000. Secondary antibodies [anti-rabbit IgG (1:2,000; sc-2004) and anti-mouse IgG (1:2,000; sc-2005)] were purchased from Santa Cruz Biotechnology, Inc. Harvested cells were washed twice with phosphate-buffered saline (PBS) and then lysed in a cell lysis buffer [20 mM Tris-HCl, $\mathrm{pH} 8.0,137 \mathrm{mM}$ $\mathrm{NaCl}, 10 \%$ glycerol, $1 \%$ Triton X-100, $1 \mathrm{mM} \mathrm{Na}_{3} \mathrm{VO}_{4}, 1 \mathrm{mM}$ $\mathrm{NaF}, 2 \mathrm{mM}$ ethylenediaminetetraacetic acid (EDTA), $200 \mathrm{nM}$ aprotinin, $20 \mu \mathrm{M}$ leupeptin, $50 \mathrm{mM}$ phenanthroline and $280 \mathrm{mM}$ benzamidine-HCl]. The protein concentration was determined using a bicinchoninic acid protein assay kit (Pierce; Thermo Fisher Scientific, Inc.). Western blotting was performed as described previously (23). Equal amounts of protein (50 $\mu \mathrm{g} / \mathrm{lane})$ were resolved by $13 \%$ sodium dodecyl sulfate-polyacrylamide gel electrophoresis; then, the proteins were transferred to nitrocellulose membranes.The membranes were incubated overnight with the primary antibodies at $4^{\circ} \mathrm{C}$ and then incubated with secondary antibodies conjugated to horseradish peroxidase at room temperature for $1 \mathrm{~h}$. $\beta$-actin was used as a loading control. Immunoblots were visualized on an X-ray film using enhanced chemiluminescence reagent (cat. no. WBKLS0100; MilliporeSigma). The blots were quantified by densitometric analysis using ImageJ v4.0 software (National Institutes of Health), and the relative expression level of each target protein was normalized using the internal standard $\beta$-actin.

Cell counting assay. Cells were seeded in 6-well culture plates (5x $10^{4} /$ well) and treated with vehicle control (DMSO; 0.06\%) or miconazole $(10,20$ or $30 \mu \mathrm{M})$ for $24 \mathrm{~h}$ at $37^{\circ} \mathrm{C}$. Afterward, the cells were detached using $0.25 \%$ trypsin/EDTA and resuspended in DMEM. Trypan blue was added to the cell suspension at $37^{\circ} \mathrm{C}$ for $5 \mathrm{~min}$ and viable cells were counted using a hemocytometer.

Flow cytometric analysis. Cell cycle analysis was performed by flow cytometry. For DNA content analysis, $\sim 1 \times 10^{6}$ cells were fixed in $80 \%$ ethanol at $4^{\circ} \mathrm{C}$ for $24 \mathrm{~h}$. The ethanol-fixed cells were stained with PI staining solution $(50 \mu \mathrm{g} / \mathrm{ml}$ PI, $0.1 \mathrm{mg} / \mathrm{ml}$ RNase A, $0.1 \%$ NP-40, $0.1 \%$ trisodium citrate) for $30 \mathrm{~min}$ at $4^{\circ} \mathrm{C}$, and then analyzed using a FACSCanto ${ }^{\mathrm{TM}}$ II flow cytometer (BD Biosciences).

Detection of LC3 translocation. To investigate the localization of green fluorescent protein-fused LC3 (GFP-LC3), U87MG cells were grown on two-well chamber slides and transfected with $1 \mu \mathrm{g}$ of GFP-LC3 plasmid, using Lipofectamine ${ }^{\circledR} 2000$ (Invitrogen; Thermo Fisher Scientific, Inc.). The GFP-LC3 
plasmid was provided by Professor Tamotsu Yoshimori (Department of Cellular Regulation Research, Institute for Microbial Diseases, Osaka University, Japan) (24). After 24 h, the medium was changed to complete growth medium, and positive stable clones were selected by incubating the cells in the presence of G418 (1 mg/ml) for 2 weeks. Stable transfected cells were grown on two-well chamber slides and treated with $20 \mu \mathrm{M}$ miconazole for $24 \mathrm{~h}$ at $37^{\circ} \mathrm{C}$. After this, the cells were washed with PBS three times and then fixed with $4 \%$ paraformaldehyde at room temperature for $10 \mathrm{~min}$. The fixed cells were washed with PBS three times and mounted with a fluorescent mounting medium (Dako; Agilent Technologies, Inc.). Images were obtained using a fluorescence microscope (Leica DM 3000; Leica Microsystems, GmbH). The GFP fluorescence intensity was analyzed using LSM 5 Image Browser software (Zeiss GmbH).

Measurement of ROS production. Intracellular ROS production was measured using a fluorescent probe, 2',7'-dichlorodihydrofluorescein diacetate $\left(\mathrm{H}_{2} \mathrm{DCFDA}\right.$; Sigma-Aldrich; Merck KGaA). U251MG cells were pretreated with miconazole at a concentration of 10 and $20 \mu \mathrm{M}$ for $10 \mathrm{~min}$ at $37^{\circ} \mathrm{C}$, followed by the addition of $10 \mu \mathrm{M} \mathrm{H}_{2}$ DCFDA and incubation for $30 \mathrm{~min}$ at room temperature. Subsequently, the cells were trypsinized, resuspended in PBS and transferred to Falcon ${ }^{\circledR}$ FACS tubes. The fluorescence emission from $\mathrm{H}_{2}$ DCFDA was analyzed using a FACSCanto ${ }^{\mathrm{TM}}$ II flow cytometer (BD Biosciences) at an excitation wavelength of $488 \mathrm{~nm}$ and emission wavelength of $520 \mathrm{~nm}$. The data were analyzed using FACSDiva software version 6.0 (BD Biosciences).

Small interfering RNA (siRNA) transfection. siRNAs against ATG5 (cat. no. sc-41445) and BiP (cat. no. sc-29338), and a scrambled siRNA (cat. no. sc-37007) were obtained from Santa Cruz Biotechnology, Inc. The sequence information of these siRNAs was not provided by Santa Cruz Biotechnology, Inc. U251MG cells were seeded in 6-well plates at a density of $2 \times 10^{5}$ cells per well and transfected with the $50 \mathrm{nM}$ siRNAs using Lipofectamine 2000. After $5 \mathrm{~h}$ of transfection, the medium was changed to complete growth medium, and then transfected cells were cultured for $20 \mathrm{~h}$ at $37^{\circ} \mathrm{C}$, followed by incubation with miconazole $(20 \mu \mathrm{M})$ for $24 \mathrm{~h}$ at $37^{\circ} \mathrm{C}$. The cells were then harvested for viability measurements and western blot analysis.

Statistical analysis. Data represent the mean \pm standard deviation of three independent experiments. Differences among groups were evaluated by one-way ANOVA followed by the post hoc Dunnett's test using SPSS 11.5 (SPSS, Inc.) software. $\mathrm{P}<0.05$ was considered to indicate a statistically ssignificant difference.

\section{Results}

Miconazole increases cell death. The cytotoxicity of miconazole against the human glioblastoma cell lines U343MG, U87MG and U251MG was examined. The cell death-inducing effect of miconazole was measured by the direct counting of viable cells following treatment with a range of miconazole concentrations (0-30 $\mu \mathrm{M})$ for $24 \mathrm{~h}$. As shown in Fig. 1A, miconazole reduced the viability of all three cell lines in a concentration-dependent manner. At a miconazole concentration of $20 \mu \mathrm{M}$, the viability of the U343MG, U87MG and U251MG cells was 44, 46 and $56 \%$ lower, respectively, than that of the cells treated with the vehicle. These results suggest that miconazole exerted cytotoxic effects against the human glioblastoma cells. The U251MG cell line, which exhibited the lowest viability in response to miconazole treatment, was selected for subsequent analyses. To determine whether the reduced cell viability was due to the induction of apoptosis, U251MG cells were pretreated with the pan-caspase inhibitor, z-VAD-fmk, for $30 \mathrm{~min}$, followed by miconazole treatment for $24 \mathrm{~h}$. Subsequently, cell viability and cell cycle analyses were performed (Fig. 1B and C). Treatment with $\mathrm{z}$-VAD-fmk did not have any significant effect on the miconazole-mediated reduction of cell viability. Similarly, treatment with z-VAD-fmk did not affect the miconazole-mediated accumulation of the sub-G1 fraction, suggesting that the cytotoxicity of miconazole was not associated with the induction of apoptosis. Cleaved caspase-3 was not detected in U251MG cells treated with miconazole (Fig. 1D). These data suggest that the cytotoxicity of miconazole was not due to caspase-dependent apoptotic cell death.

Miconazole induces autophagy in human glioblastoma cells. As autophagy is a major mode of cell death that occurs in response to adverse cellular stress, whether miconazole induces autophagy was investigated using the autophagic marker LC3-II. Treatment with miconazole significantly increased the level of LC3-II in U251MG cells in a time- and concentration-dependent manner (Fig. 2A and B, respectively), suggesting that miconazole induces autophagy. The examination of cell lines not of glioblastoma origin, namely MDA-MD-231 breast cancer and A549 lung cancer cell lines, revealed that they also exhibited reduced viability and a marked increase in the level of LC3-II following miconazole treatment (Fig. S1). The immunofluorescent expression pattern of LC3 in stable GFP-LC3-transfected U87MG cells was also examined. The number of GFP-LC3 puncta was significantly increased in the miconazole-treated cells (Fig. S2). To confirm the involvement of autophagy in the cytotoxic effect of miconazole, the autophagy inhibitor 3-MA and an ATG5-specific siRNA were used to suppress autophagy. 3-MA inhibited the LC3-I-to-LC3-II conversion and cell death in miconazole-treated cells (Fig. 2C). In addition, transfection of the cells with ATG5 siRNA resulted in the significant inhibition of miconazole-induced LC3-II accumulation and cell growth (Fig. 2D).

The miconazole-induced autophagic flux was further investigated in the presence or absence of the autophagosome-lysosome fusion inhibitors, Baf A1 and CQ. Pretreatment with Baf A1 or CQ alone increased the level of LC3-II, and the addition of miconazole caused a further increase in LC3-II, suggesting that miconazole induced autophagic flux. Pretreatment with Baf A1 and CQ also diminished the miconazole-induced cell death (Fig. 2C). These data demonstrate that autophagy plays a crucial role in miconazole-induced cell death.

Endoplasmic reticulum (ER) stress is involved in miconazole-induced autophagy. To determine whether miconazole 


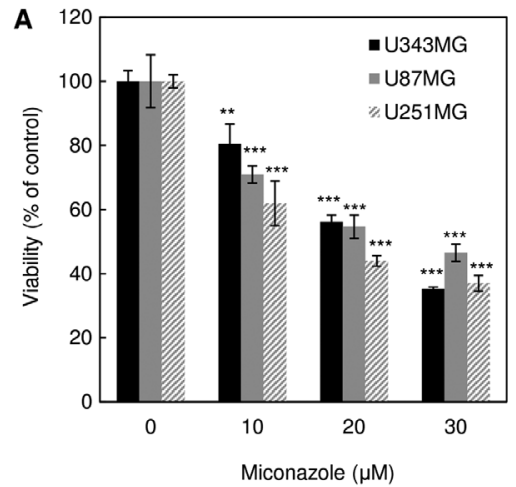

C
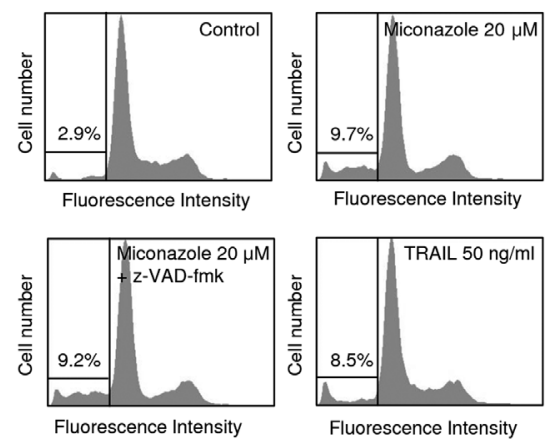

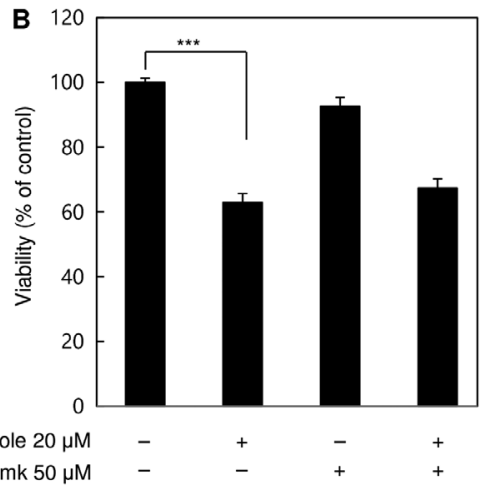

D
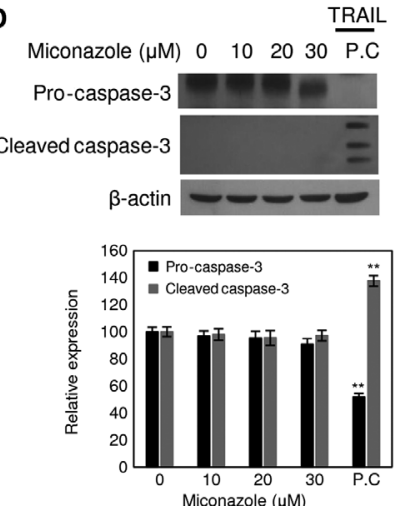

Figure 1. Effects of miconazole on the viability of human glioblastoma cell lines. (A) Viability of the U343MG, U87MG and U251MG human glioblastoma cell lines following treatment with various concentrations of miconazole for $24 \mathrm{~h}$. (B) Viability of U251MG cells, pretreated with $50 \mu \mathrm{M} \mathrm{z}$-VAD-fmk for 30 min before combined treatment wth $20 \mu \mathrm{M}$ miconazole for $24 \mathrm{~h}$. (C) U251MG cells, pretreated with z-VAD-fmk for 30 min and then treated with $20 \mu \mathrm{M}$ miconazole for $24 \mathrm{~h}$, and the sub-G1 population was determined by flow cytometric analysis following PI staining. The percentage of the sub-G1 population in each cell line is indicated (n=3). (D) Western blotting of procaspase-3 and cleaved caspase-3 in U251MG cells following treatment with miconazole. $\beta$-actin was used as a loading control, and cells treated with TRAIL were used as an apoptosis-positive control. Densitometric analysis of the of western blots is shown in the bar graph. All graphical data are the mean \pm standard deviation of three independent experiments. ${ }^{* *} \mathrm{P}<0.01$ and ${ }^{* * * *} \mathrm{P}<0.001$ vs. $0 \mu \mathrm{M}$ miconazole. TRAIL, tumor necrosis factor-related apoptosis-inducing ligand; PC, positive control.

induces autophagy via the activation of ER stress in human glioblastoma cells, the levels of ER stress response markers, namely BiP, IRE1 $\alpha$, p-eIF2 $\alpha$ and CHOP, were examined. Miconazole increased the levels of these ER stress response proteins in a concentration-dependent manner (Fig. 3A). To further investigate whether ER stress is involved in miconazole-induced autophagy, 4-PBA, a chemical inhibitor of ER stress, was used. U251MG cells were pretreated with 0.5 or $1 \mathrm{mM} 4-\mathrm{PBA}$ for $30 \mathrm{~min}$, followed by $20 \mu \mathrm{M}$ miconazole treatment for $24 \mathrm{~h}$. The increase in the LC3-II level that was observed after miconazole treatment was significantly inhibited by pretreatment with 4-PBA in a concentration-dependent manner. Pretreatment with 4-PBA also attenuated miconazole-induced cell death (Fig. 3B). Transfection with BiP siRNA attenuated the miconazole-induced increase in LC3-II levels in U251MG cells. The inhibition of ER stress was associated with a simultaneous reduction in miconazole-induced cell death (Fig. 3C). These data suggest that ER stress plays a key role in miconazole-induced autophagic cell death.

Miconazole induces ROS production in human glioblastoma cells. Whether miconazole induces ROS production in human glioblastoma cells was tested using flow cytometry. As shown in Fig. 4A, the treatment of U251MG cells with miconazole for 10 min caused a marked increase in the emission of fluorescence by $\mathrm{H}_{2}$ DCFDA, suggesting that miconazole induces ROS production. To further confirm the role of ROS in miconazole-induced autophagic cell death, cells were pretreated with $5 \mathrm{mM}$ NAC, a ROS scavenger, for $2 \mathrm{~h}$, followed by treatment with 10 or $20 \mu \mathrm{M}$ miconazole for $24 \mathrm{~h}$ at $37^{\circ} \mathrm{C}$. As shown in Fig. 4B, miconazole treatment increased cell death in a concentration-dependent manner, while cotreatment with NAC attenuated the miconazole-induced cell death. Furthermore, cotreatment with miconazole and NAC led to significant reductions in LC3-II levels. These results indicate that ROS are involved in the miconazole-induced autophagic cell death of U251MG cells.

To further examine whether miconazole-induced ROS production induces ER stress, cells were treated with miconazole alone or with NAC for $24 \mathrm{~h}$. The cotreatment with NAC significantly blocked ER stress, as indicated by lower levels of the ER stress markers BiP and IRE1 $\alpha$ (Fig. 4C). These findings are consistent with the increase in viability of miconazole-treated U251MG cells observed when the cells were cotreated with NAC. These results indicate that ROS production and ER stress are involved in the miconazole-induced autophagic death of U251MG cells.

\section{Discussion}

Miconazole has been shown to inhibit the proliferation of human cancer cells via cell cycle arrest, the induction of 
A

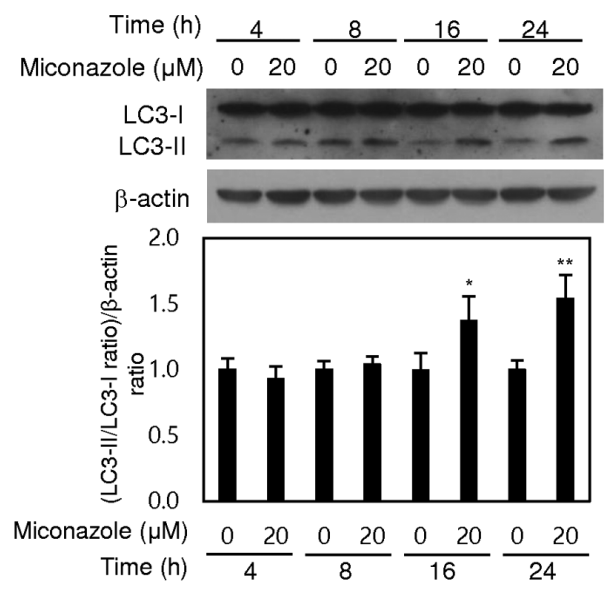

C
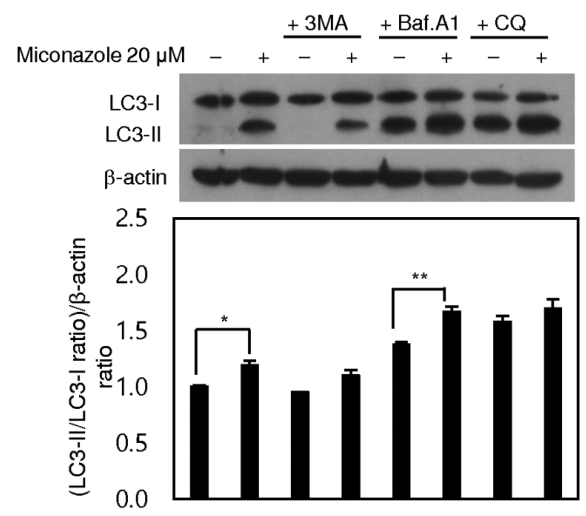

Miconazole $(\mu \mathrm{M}) 0 \quad 20 \frac{0 \quad 20}{+3 \mathrm{MA}} \frac{0 \quad 20}{+ \text { Baf.A1 }} \frac{0 \quad 20}{+\mathrm{CQ}}$
B
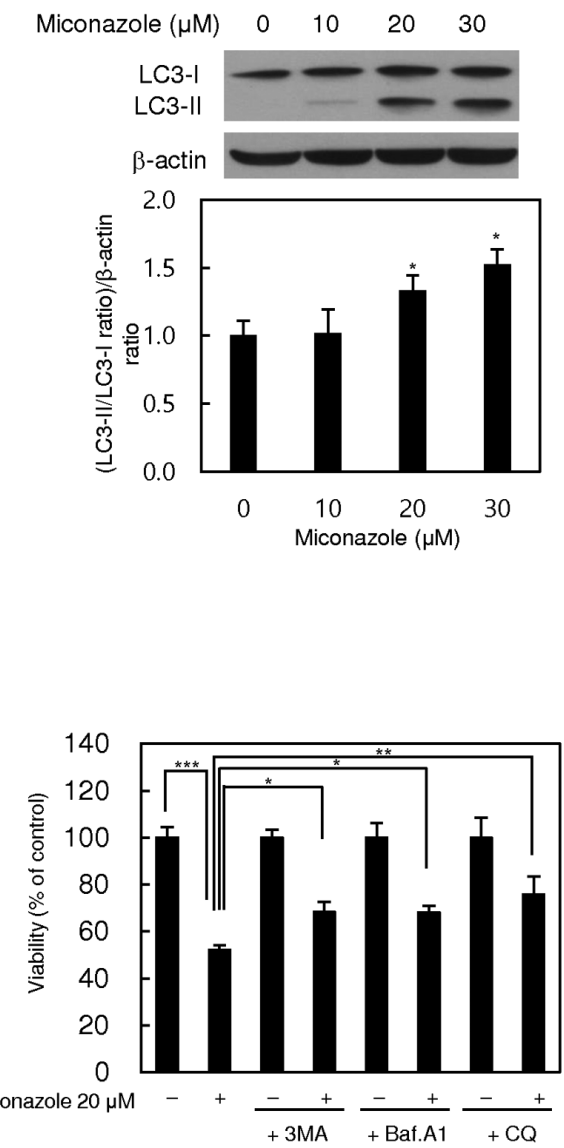

Miconazole $20 \mu \mathrm{M}-+\frac{-+}{+3 \mathrm{MA}} \frac{-+}{+ \text { Baf.A1 }} \frac{-+}{+\mathrm{CQ}}$

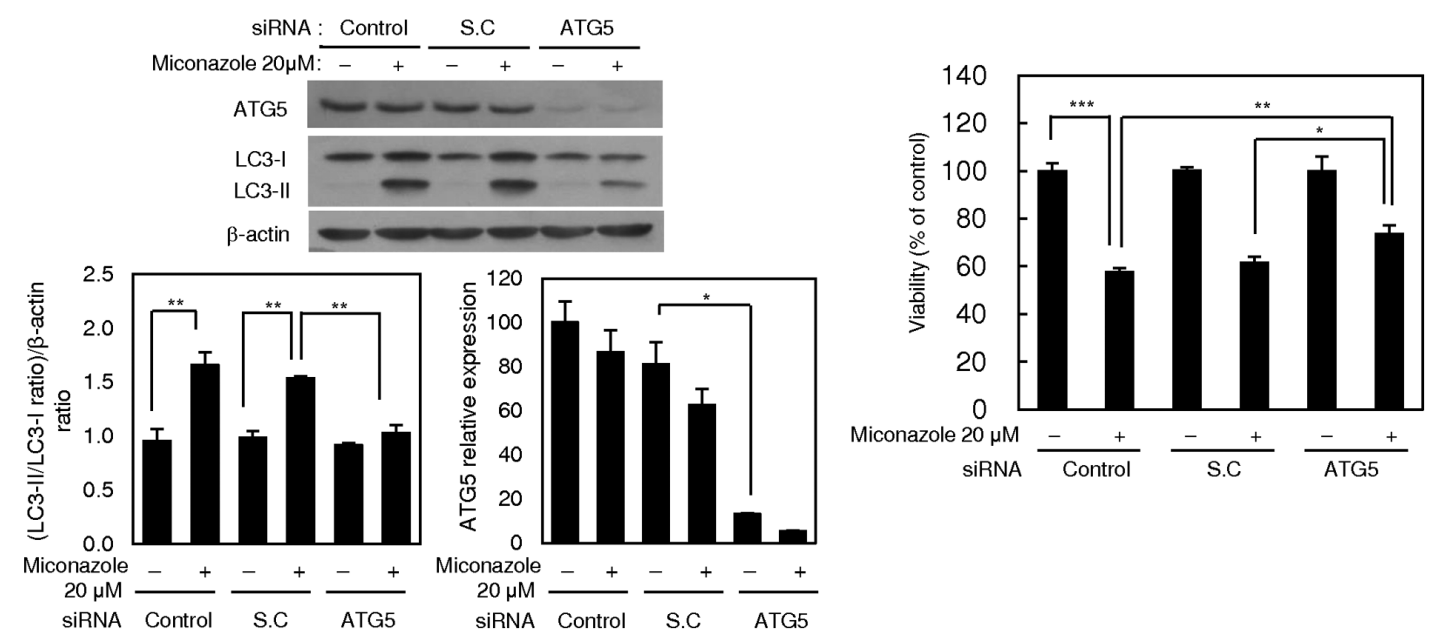

D

Figure 2. Autophagy-inducing effects of miconazole. Expression of the LC3 protein in U251MG cells treated with (A) $20 \mu \mathrm{M}$ miconazole for the indicated times or (B) various miconazole concentrations for $24 \mathrm{~h}$, as determined by western blotting. $\beta$-actin was used as a loading control. Densitometric analysis of the western blots is shown in the bar graphs. (C) Expression of LC3 protein in U251MG cells treated with $20 \mu$ M miconazole alone or cotreated with 1 mM 3-MA, $20 \mathrm{nM}$ Baf A1 or $50 \mu \mathrm{M} \mathrm{CQ}$ for $24 \mathrm{~h}$, and the viability of these cells. LC3 expression was determined by western blotting using $\beta$-actin as a loading control. Densitometric analysis of the western blots is shown in the bar graph. (D) Expression of ATG5 and LC3 proteins in U251MG cells transiently transfected with an ATG5 siRNA or SC siRNA, and treated with $20 \mu \mathrm{M}$ miconazole or vehicle for $24 \mathrm{~h}$, and the viability of these cells. ATG5 and LC3 expression was determined by western blotting using $\beta$-actin as a loading control. Densitometric analysis of the western blots is shown in the bar graph. All graphical data are the mean \pm standard deviation of three independent experiments. ${ }^{*} \mathrm{P}<0.05,{ }^{* *} \mathrm{P}<0.01$ and ${ }^{* * *} \mathrm{P}<0.001$ vs. $0 \mu \mathrm{M}$ miconazole or as indicated. LC3, microtubule-associated protein light chain 3; 3-MA, 3-methyladenine; Baf A1, bafilomycin A1; CQ, chloroquine; siRNA, small interfering RNA; SC, scrambled control.

ROS production and the release of intracellular $\mathrm{Ca}^{2+}(13)$. To date, apoptosis has been implicated as the main mechanism of miconazole-induced cell death $(14,25)$. To the best of our knowledge, the present study is the first to report miconazole-induced autophagy in human glioblastoma cells. Mechanistically, the results indicate that miconazole induced 
A

B
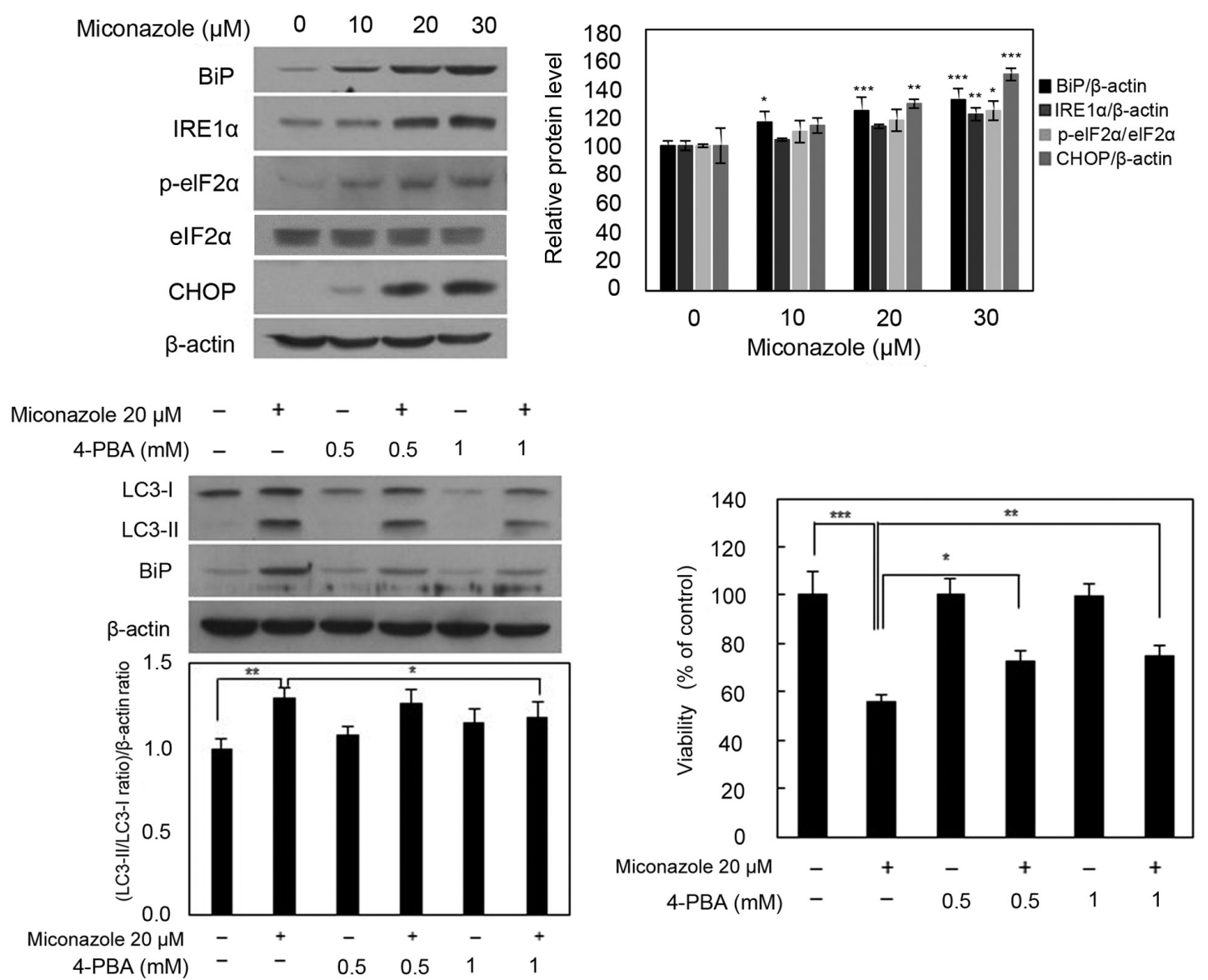

C
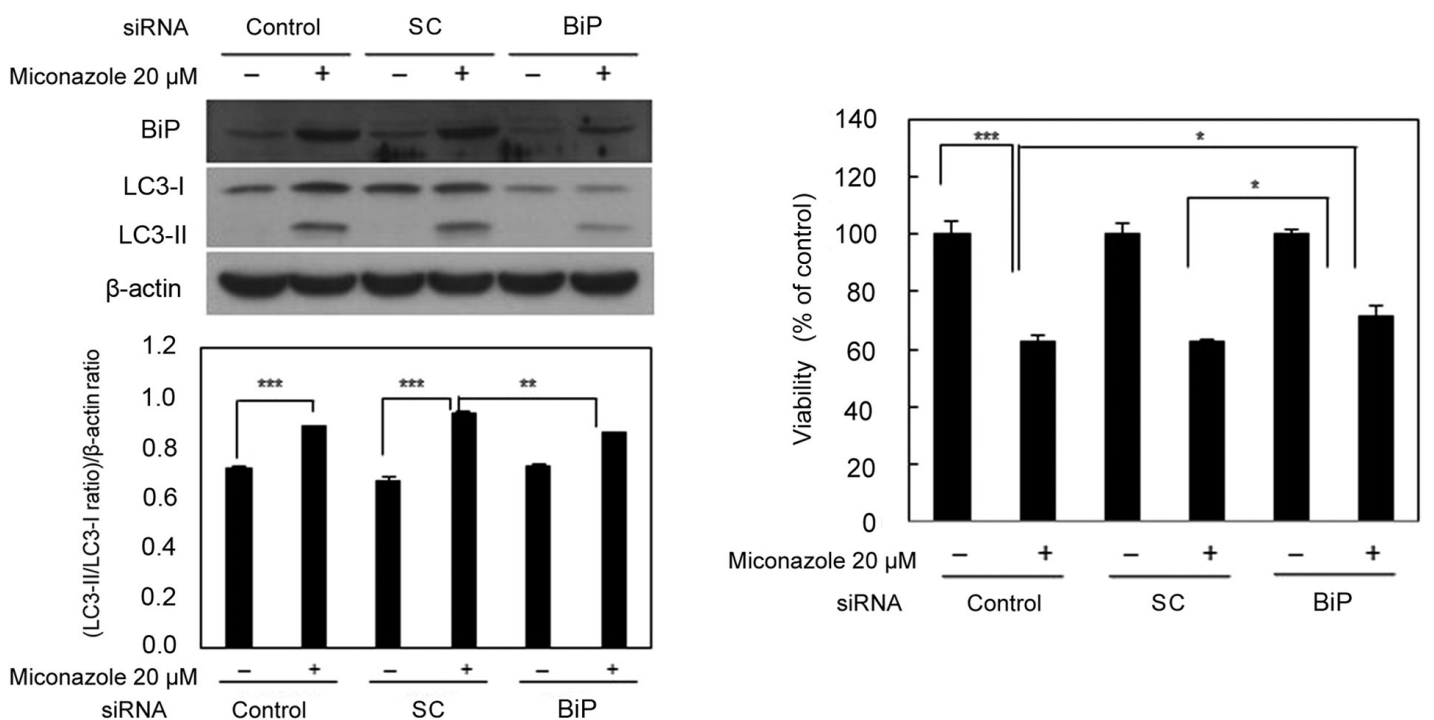

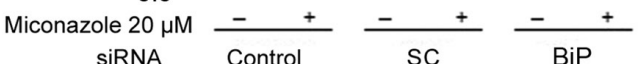

Figure 3. ER stress-inducing effects of miconazole. (A) Expression of ER stress-associated proteins in U251MG cells exposed to the indicated concentrations of miconazole for $24 \mathrm{~h}$, as determined by western blotting. Densitometric analysis of the western blots is shown in the bar graph. Data are the mean \pm SD of three independent experiments. (B) Levels of BiP and LC3-I and II proteins in U251MG cells pretreated with 4-PBA for 30 min and then treated with $20 \mu \mathrm{M}$ miconazole for $24 \mathrm{~h}$. Densitometric analysis of the western blots is shown in the bar graph $(\mathrm{n}=3)$. Cell viability is expressed as the percentage of control $\pm \mathrm{SD}$ for pooled data from three experiments, each performed in triplicate. (C) Levels of BiP and LC3-I and II proteins in cells transfected with BiP siRNA or SC siRNA and treated with miconazole for $24 \mathrm{~h}$, as determined by western blotting. Densitometric analysis of the western blots is shown in the bar graph $(\mathrm{n}=3)$. Cell viability data are the mean $\pm \mathrm{SD}$ of three independent experiments $(\mathrm{n}=3) .{ }^{*} \mathrm{P}<0.05,{ }^{* *} \mathrm{P}<0.01$ and ${ }^{* * *} \mathrm{P}<0.001$ vs. $0 \mu \mathrm{M}$ miconazole or as indicated. ER, endoplasmic reticulum; BiP, binding immunoglobulin protein; LC3, microtubule-associated protein light chain 3; 4-PBA, 4-phenylbutyric acid; siRNA, small interfering RNA; SC, scrambled control; IRE1 $\alpha$, inositol-requiring enzyme 1 $\alpha$; p-, phospho-; eIF2 $\alpha$, eukaryotic initiation factor $2 \alpha$.

autophagy via the ROS-mediated activation of ER stress. Autophagy is a dynamic process comprising the sequestration of cytoplasmic organelles and proteins into autophagosomes, which fuse with lysosomes, enabling the degradation of 
A

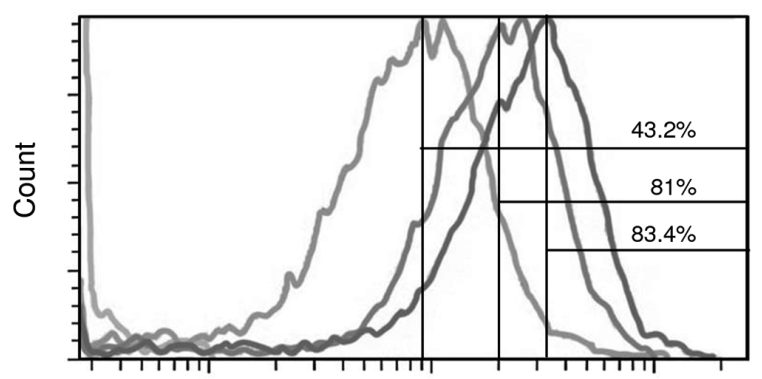

- Vehicle control

- Miconazole $10 \mu \mathrm{M}$

- Miconazole $20 \mu \mathrm{M}$

FITC-A

B
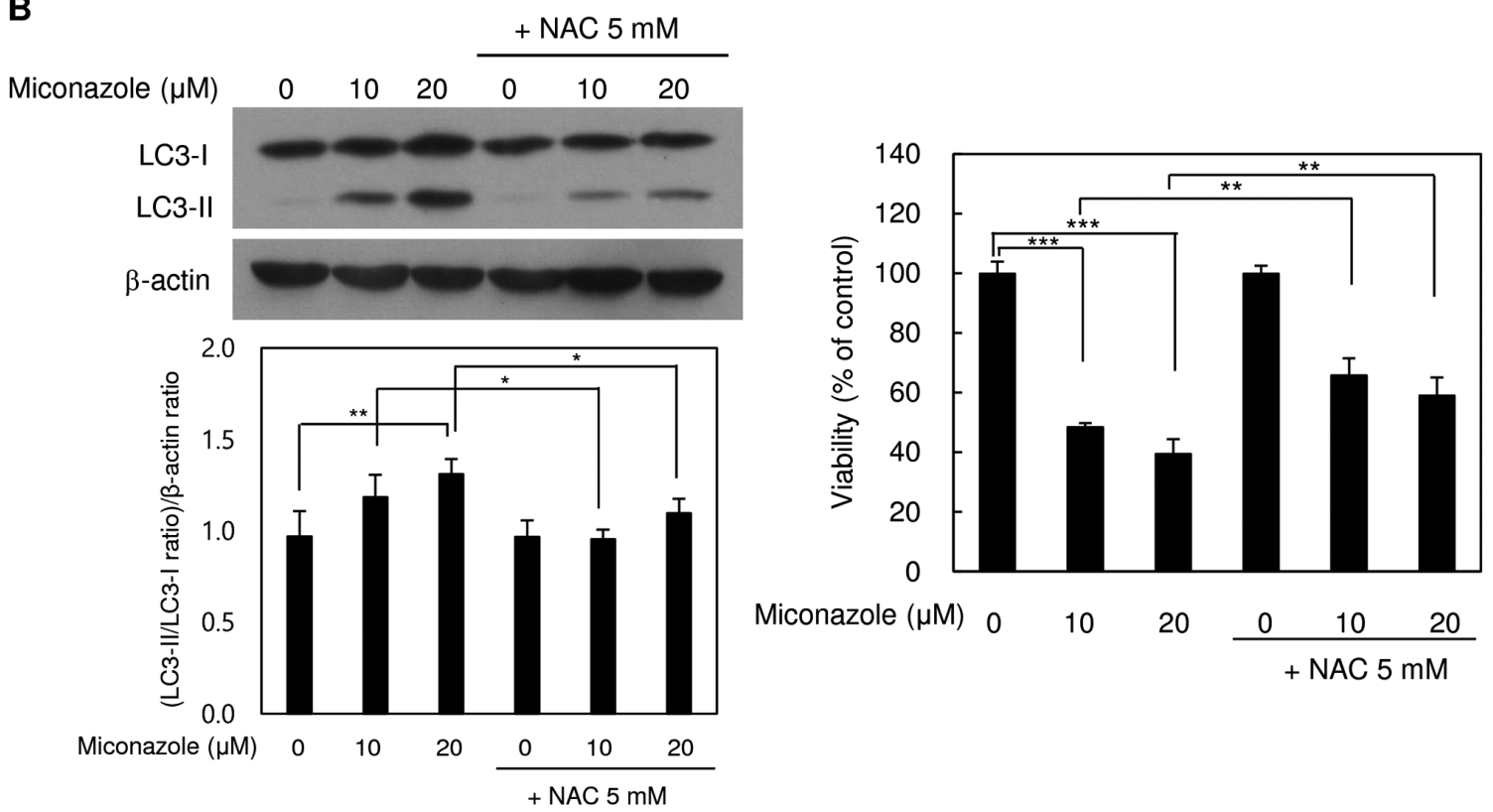

C
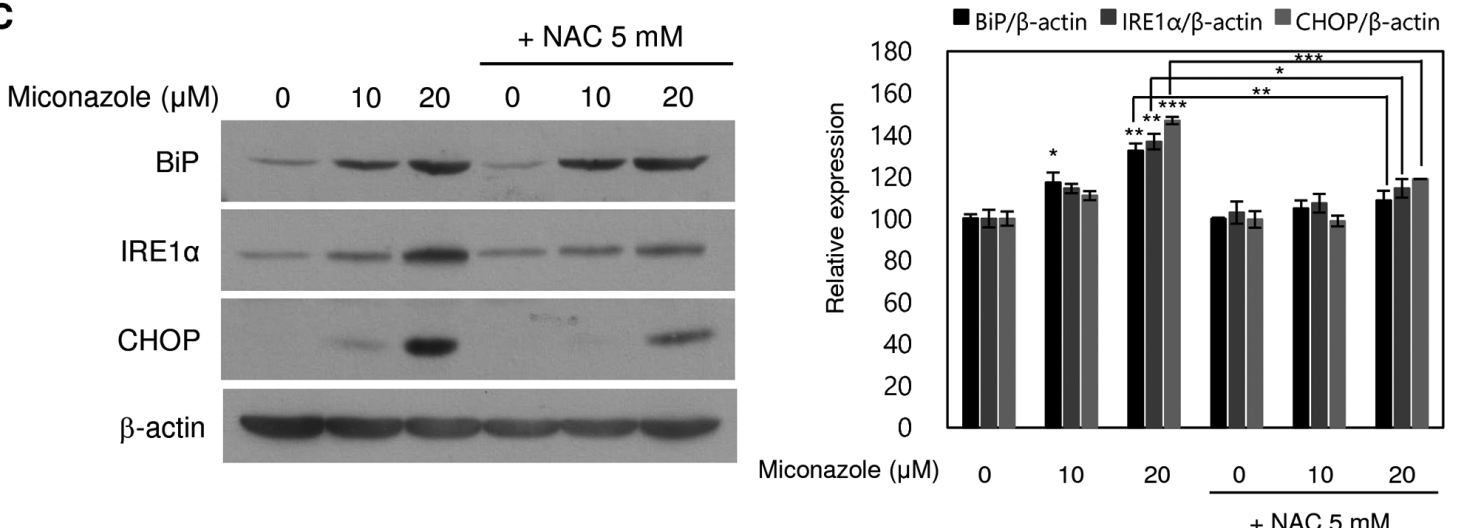

Figure 4. ROS- and ER stress-inducing effects of miconazole in relation to autophagic cell death. (A) ROS production in cells treated with miconazole for $10 \mathrm{~min}$, as measured by flow cytometry. Fluorescence intensity is directly proportional to the quantity of ROS species in the cells. (B) Levels of LC3-I and LC3-II proteins in U251MG cells treated with miconazole in the presence or absence of $5 \mathrm{mM}$ NAC, as determined by western blotting and densitometry using $\beta$-actin as a loading control. (C) Levels of BiP, IRE1 $\alpha$ and CHOP proteins in cells pretreated with $5 \mathrm{mM} \mathrm{NAC}$ for $2 \mathrm{~h}$ and then treated with miconazole at the indicated concentrations for $24 \mathrm{~h}$, as determined by western blotting using $\beta$-actin as a loading control. Densitometric analysis of the western blots is shown in the bar graph. Densitometric and cell viability data are the mean \pm standard deviation of three independent experiments. ${ }^{*} \mathrm{P}<0.05,{ }^{* *} \mathrm{P}<0.01$ and ${ }^{* * * *} \mathrm{P}<0.001$. ROS, reactive oxygen species; ER, endoplasmic reticulum; LC3, microtubule-associated protein light chain 3; NAC, $N$-acetylcysteine; BiP, binding immunoglobulin protein; IRE1 $\alpha$, inositol-requiring enzyme $1 \alpha$

target proteins by lysosomal hydrolases. However, increased autophagy can directly induce cell death $(3,7)$. It has been reported that excessive autophagic activity, which causes the overconsumption of critical cellular components, is responsible for type II nonapoptotic programmed cell death, also known as autophagic cell death (26). The present study demonstrated that miconazole triggered autophagy-mediated cell death in U251MG cells, as well as in MDA-MB-231 and A549 cells, as indicated by an increase in LC3-II levels. Cleaved caspase-3, a marker of apoptosis, was not detected in U251MG cells following miconazole treatment, and no change in the cytotoxicity of miconazole was observed when the cells were cotreated with z-VAD-fmk, a pan-caspase inhibitor. However, although miconazole induced LC3-II expression, 
ATG5 expression was unaffected. Other studies have also observed no change in the protein expression level of ATG5 in experimentally induced autophagy $(27,28)$. In addition, the activity of ATG5 is reportedly regulated by phosphorylation (29). By contrast, the inhibition of miconazole-mediated autophagy via the knockdown of ATG5 or using autophagy inhibitors resulted in the decreased conversion of LC3-I to LC3-II and the restoration of cell viability. These results suggest that autophagy may be an essential mechanism in miconazole-induced cell death but do not eliminate the potential existence of other mechanisms. For example, miconazole has been reported to inhibit fumarate hydratase activity and enhance cisplatin-induced cell death in gastric cancer (30). In addition, miconazole has been demonstrated to induce cell death via the accumulation of $\mathrm{Ca}^{2+}$ in human breast cancer (31). Caspase-independent mechanisms of cell death also exist and may play roles in alternative anticancer therapeutic strategies, such as alteration of the mitochondrial permeability transition (32) or cytotoxic T-lymphocyte granule exocytosis via the Fas/Fas ligand pathway (33). Although the occurrence of caspase-independent apoptosis was not investigated in the present study, cell death did not increase when miconazole was supplemented with z-VAD-fmk.

Previous studies have shown that the ER plays an essential role in the process of autophagy and that autophagy is critical for the maintenance of ER homeostasis $(34,35)$. In mammalian cells, ER stress promotes autophagy, enabling the removal of misfolded proteins (36-39). The mechanism of miconazole-induced ER stress is unknown. In the present study, ER stress signaling was shown to participate in the miconazole-induced autophagic cell death. To confirm the role of ER stress in miconazole-induced cell death, 4-PBA and a BiP siRNA were used, and the inhibition of ER stress was demonstrated to prevent the miconazole-mediated induction of autophagic cell death.

The results of the present study also demonstrated that ROS, known as regulators of autophagy (40), are involved in miconazole-induced autophagy. The excessive production of ROS, including superoxide radicals, hydrogen peroxide and hydroxyl radicals, causes oxidative stress and, ultimately, cell death (41). ROS also act as second-messenger signaling molecules, regulating multiple cell functions, including autophagy and apoptosis (42-44). The induction of intracellular oxidative stress by miconazole has been demonstrated in rat neonatal cardiomyocytes and bladder cancer cells, as well as in Candida albicans and other fungi (18,25,45-48). The present study revealed that the NAC-mediated scavenging of miconazole-induced ROS decreased the levels of LC3-II and molecular markers of ER stress. These data suggest that the increased production of intracellular ROS in miconazole-treated cells causes ER stress, which in turn induces autophagic cell death.

In summary, the present study indicate that miconazole induced autophagy-mediated cell death in glioblastoma cell lines and that the induction of intracellular ROS production and ER stress might be the underlying mechanism by which autophagy was activated. The results support the chemotherapeutic potential of miconazole and provide the first evidence of the involvement of autophagy in miconazole-induced cell death.

\section{Acknowledgements}

Not applicable.

\section{Funding}

This study was supported by the National Research Foundation of Korea (grants nos. 2016R1A2B1012055, 2018R1A2B5A01023660 and 2020R1H1A2102379), funded by the Korean Government (MSIP).

\section{Availability of data and materials}

All data generated or analyzed during this study are included in this published article.

\section{Authors' contributions}

HJJ performed the experiments and analyzed the results. WKB analyzed and interpreted the data and wrote the manuscript. IS, BKJ and SIS were involved in project development, data analysis and editing the manuscript. HJJ and SIS confirm the authenticity of all the raw data. All authors read and approved the final manuscript.

\section{Ethics approval and consent to participate}

Not applicable.

\section{Patient consent for publication}

Not applicable.

\section{Competing interests}

The authors declare that they have no competing interests.

\section{References}

1. Mizushima N and Komatsu M: Autophagy: Renovation of cells and tissues. Cell 147: 728-741, 2011.

2. Levine B and Klionsky DJ: Development by self-digestion: Molecular mechanisms and biological functions of autophagy. Dev Cell 6: 463-477, 2004.

3. He C and Klionsky DJ: Regulation mechanisms and signaling pathways of autophagy. Annu Rev Genet 43: 67-93, 2009.

4. Shao Y, Gao Z, Marks PA and Jiang X: Apoptotic and autophagic cell death induced by histone deacetylase inhibitors. Proc Natl Acad Sci USA 101: 18030-18035, 2004.

5. Mazure NM and Pouysségur J: Hypoxia-induced autophagy: Cell death or cell survival? Curr Opin Cell Biol 22: 177-180, 2010

6. Descloux C, Ginet V, Clarke PG, Puyal J and Truttmann AC: Neuronal death after perinatal cerebral hypoxia-ischemia: Focus on autophagy-mediated cell death. Int J Dev Neurosci 45: 75-85, 2015.

7. Maiuri MC, Zalckvar E, Kimchi A and Kroemer G: Self-eating and self-killing: Crosstalk between autophagy and apoptosis. Nat Rev Mol Cell Biol 8: 741-752, 2007.

8. Mathew R, Karantza-Wadsworth V and White E: Role of autophagy in cancer. Nat Rev Cancer 7: 961-967, 2007.

9. Furtado CM, Marcondes MC, Sola-Penna M, de Souza ML and Zancan P: Clotrimazole preferentially inhibits human breast cancer cell proliferation, viability and glycolysis. PLoS One 7: e30462, 2012.

10. Gupta A, Unadkat JD and Mao Q: Interactions of azole antifungal agents with the human breast cancer resistance protein (BCRP). J Pharm Sci 96: 3226-3235, 2007. 
11. Shahbazfar AA, Zare P, Ranjbaran M, Tayefi-Nasrabadi H, Fakhri O, Farshi Y, Shadi S and Khoshkerdar A: A survey on anticancer effects of artemisinin, iron, miconazole, and butyric acid on 5637 (bladder cancer) and 4T1 (Breast cancer) cell lines. J Cancer Res Ther 10: 1057-1062, 2014.

12. Park JY, Jung HJ, Seo I, Jha BK, Suh SI, Suh MH and Baek WK Translational suppression of HIF-1 $\alpha$ by miconazole through the mTOR signaling pathway. Cell Oncol (Dordr) 37: 269-279, 2014

13. Chang HT, Chen WC, Chen JS, Lu YC, Hsu SS, Wang JL, Cheng HH, Cheng JS, Jiann BP, Chiang AJ, et al: Effect of miconazole on intracellular $\mathrm{Ca}^{2+}$ levels and proliferation in human osteosarcoma cells. Life Sci 76: 2091-2101, 2005.

14. Wu CH, Jeng JH, Wang YJ, Tseng CJ, Liang YC, Chen $\mathrm{CH}$, Lee HM, Lin JK, Lin CH, Lin SY, et al: Antitumor effects of miconazole on human colon carcinoma xenografts in nude mice through induction of apoptosis and G0/G1 cell cycle arrest. Toxicol Appl Pharmacol 180: 22-35, 2002.

15. Yuan SY, Shiau MY, Ou YC, Huang YC, Chen CC, Cheng CL, Chiu KY, Wang SS and Tsai KJ: Miconazole induces apoptosis via the death receptor 5-dependent and mitochondrial-mediated pathways in human bladder cancer cells. Oncol Rep 37: 3606-3616, 2017.

16. Chengzhu WU, Gao M, Shen L, Bohan LI, Bai X, Gui J, Hongmei LI, Huo Q and Tao MA: Miconazole triggers various forms of cell death in human breast cancer MDA-MB-231 cells. Pharmazie 74: 290-294, 2019.

17. Kobayashi D, Kondo K, Uehara N, Otokozawa S, Tsuji N, Yagihashi A and Watanabe N: Endogenous reactive oxygen species is an important mediator of miconazole antifungal effect. Antimicrob Agents Chemother 46: 3113-3117, 2002.

18. Lee KP, Kim JE and Park WH: Cytoprotective effect of rhamnetin on miconazole-induced H9c2 cell damage. Nutr Res Pract 9 586-591, 2015.

19. Yeo IJ, Yun J, Son DJ, Han SB and Hong JT: Antifungal drug miconazole ameliorated memory deficits in a mouse model of LPS-induced memory loss through targeting iNOS. Cell Death Dis 11: 623, 2020

20. Chen LD, Liu ZH, Zhang LF, Yao JN and Wang CF: Sanggenon C induces apoptosis of colon cancer cells via inhibition of $\mathrm{NO}$ production, iNOS expression and ROS activation of the mitochondrial pathway. Oncol Rep 38: 2123-2131, 2017.

21. Holotiuk VV, Kryzhanivska AY, Churpiy IK, Tataryn BB and Ivasiutyn DY: Role of nitric oxide in pathogenesis of tumor growth and its possible application in cancer treatment. Exp Oncol 41: 210-215, 2019.

22. Liu R, Li J, Zhang T, Zou L, Chen Y, Wang K, Lei Y, Yuan K, Li Y, Lan J, et al: Itraconazole suppresses the growth of glioblastoma through induction of autophagy: Involvement of abnormal cholesterol trafficking. Autophagy 10: 1241-1255, 2014.

23. Jung HJ, Seo I, Casciello F, Jacquelin S, Lane SW, Suh SI, Suh MH, Lee JS and Baek WK: The anticancer effect of chaetocin is enhanced by inhibition of autophagy. Cell Death Dis 7: e2098, 2016.

24. Kabeya Y, Mizushima N, Ueno T, Yamamoto A, Kirisako T, Noda T, Kominami E, Ohsumi Y and Yoshimori T: LC3, a mammalian homologue of yeast Apg8p, is localized in autophagosome membranes after processing. EMBO J 19: 5720-5728, 2000.

25. Won KJ, Lin HY, Jung S, Cho SM, Shin HC, Bae YM, Lee SH, Kim HJ, Jeon BH and Kim B: Antifungal miconazole induces cardiotoxicity via inhibition of APE/Ref-1-related pathway in rat neonatal cardiomyocytes. Toxicol Sci 126: 298-305, 2012.

26. Portt L, Norman G, Clapp C, Greenwood M and Greenwood MT: Anti-apoptosis and cell survival: A review. Biochim Biophys Acta 1813: 238-259, 2011

27. Tanaka S, Hikita H, Tatsumi T, Sakamori R, Nozaki Y, Sakane S, Shiode Y, Nakabori T, Saito Y, Hiramatsu N, et al: Rubicon inhibits autophagy and accelerates hepatocyte apoptosis and lipid accumulation in nonalcoholic fatty liver disease in mice. Hepatology 64: 1994-2014, 2016.

28. Basu A: Regulation of autophagy by protein kinase $\mathrm{C}-\varepsilon$ in breast cancer cells. Int J Mol Sci 21: 4247, 2020.

29. Keil E, Höcker R, Schuster M, Essmann F, Ueffing N, Hoffman B, Liebermann DA, Pfeffer K, Schulze-Osthoff K and Schmitz I: Phosphorylation of Atg5 by the Gadd45 3 -MEKK4-p38 pathway inhibits autophagy. Cell Death Differ 20: 321-332, 2013.

30. Yu HE, Wang F, Yu F, Zeng ZL, Wang Y, Lu YX, Jin Y, Wang DS Qiu MZ, Pu HY, et al: Suppression of fumarate hydratase activity increases the efficacy of cisplatin-mediated chemotherapy in gastric cancer. Cell Death Dis 10: 413, 2019.
31. Roan CJ, Chou CT, Liang WZ, Chang HT, Kuo DH, Kuo CC, Chen FA, Shieh P and Jan CR: Effect of miconazole on $\left[\mathrm{Ca}^{2+}\right]$ $\mathrm{i}$ and cytotoxicity in ZR-75-1 human breast cancer cells. Chin J Physiol 58: 377-384, 2015

32. Hirsch T, Marchetti P, Susin SA, Dallaporta B, Zamzami N, Marzo I, Geuskens M and Kroemer G: The apoptosis-necrosis paradox. Apoptogenic proteases activated after mitochondrial permeability transition determine the mode of cell death. Oncogene 15 1573-1581, 1997.

33. Sarin A, Williams MS, Alexander-Miller MA, Berzofsky JA, Zacharchuk CM and Henkart PA: Target cell lysis by CTL granule exocytosis is independent of ICE/Ced-3 family proteases. Immunity 6: 209-215, 1997.

34. Yorimitsu T and Klionsky DJ: Endoplasmic reticulum stress: A new pathway to induce autophagy. Autophagy 3: 160-162, 2007.

35. Ding WX, Ni HM, Gao W, Hou YF, Melan MA, Chen X, Stolz DB, Shao ZM and Yin XM: Differential effects of endoplasmic reticulum stress-induced autophagy on cell survival. J Biol Chem 282: 4702-4710, 2007

36. Kouroku Y, Fujita E, Tanida I, Ueno T, Isoai A, Kumagai H, Ogawa S, Kaufman RJ, Kominami E and Momoi T: ER stress (PERK/eIF2alpha phosphorylation) mediates the polyglutamine-induced LC3 conversion, an essential step for autophagy formation. Cell Death Differ 14: 230-239, 2007.

37. Yin JJ, Xie G, Zhang N and Li Y: Inhibiting autophagy promotes endoplasmic reticulum stress and the ROS induced nod like receptor 3 dependent proinflammatory response in HepG2 cells. Mol Med Rep 14: 3999-4007, 2016.

38. Ding WX, Ni HM, Gao W, Yoshimori T, Stolz DB, Ron D and Yin XM: Linking of autophagy to ubiquitin-proteasome system is important for the regulation of endoplasmic reticulum stress and cell viability. Am J Pathol 171: 513-524, 2007.

39. Hwang MS and Baek WK: Glucosamine induces autophagic cell death through the stimulation of ER stress in human glioma cancer cells. Biochem Biophys Res Commun 399: 111-116, 2010

40. Chen Y, Azad MB and Gibson SB: Superoxide is the major reactive oxygen species regulating autophagy. Cell Death Differ 16: 1040-1052, 2009.

41. Fleury C, Mignotte B and Vayssière JL: Mitochondrial reactive oxygen species in cell death signaling. Biochimie 84: 131-141, 2002.

42. Miki H, Uehara N, Kimura A, Sasaki T, Yuri T, Yoshizawa K and Tsubura A: Resveratrol induces apoptosis via ROS-triggered autophagy in human colon cancer cells. Int J Oncol 40: 1020-1028, 2012.

43. Poillet-Perez L, Despouy G, Delage-Mourroux R and Boyer-Guittaut M: Interplay between ROS and autophagy in cancer cells, from tumor initiation to cancer therapy. Redox Biol 4: 184-192, 2015

44. Zhou DR, Eid R, Miller KA, Boucher E, Mandato CA and Greenwood MT: Intracellular second messengers mediate stress inducible hormesis and programmed cell death: A review. Biochim Biophys Acta Mol Cell Res 1866: 773-792, 2019.

45. Delattin N, Cammue BP and Thevissen K: Reactive oxygen species-inducing antifungal agents and their activity against fungal biofilms. Future Med Chem 6: 77-90, 2014

46. Kumar CG and Poornachandra Y: Biodirected synthesis of Miconazole-conjugated bacterial silver nanoparticles and their application as antifungal agents and drug delivery vehicles. Colloids Surf B Biointerfaces 125: 110-119, 2015.

47. Zhu CX, Yan L, Wang XJ, Miao Q, Li XX, Yang F, Cao YB, Gao PH, Bi XL and Jiang YY: Transposition of the Zorro2 retrotransposon is activated by miconazole in Candida albicans. Biol Pharm Bull 37: 37-43, 2014.

48. Tsai TF, Chen PC, Lin YC, Chou KY, Chen HE, Ho CY, Lin JF and Hwang TI: Miconazole contributes to NRF2 activation by noncanonical P62-KEAP1 pathway in bladder cancer cells. Drug Des Devel Ther 14: 1209-1218, 2020.

This work is licensed under a Creative Commons Attribution-NonCommercial-NoDerivatives 4.0 International (CC BY-NC-ND 4.0) License. 